From this it follows that the critical temperature of hydrogen is $40^{\circ} \cdot 4$ or $-232^{\circ} \cdot 6 \mathrm{C}$., which is not far from the value which was found for it experimentally, viz. $-234^{\circ} \cdot 5 \mathrm{C}$. (loc. cit.).

From these researches it also appears that it is possible to liquefy hydrogen by the method of free expansion without cooling the gas to $-200^{\circ} \mathrm{C}$. Provided the heat insulation were sufficiently perfect, it should be necessary to cool the apparatus only to - $100^{\circ}$, a temperature which could be attained by means of solid carbonic acid evaporating under reduced pressure, before allowing the hydrogen to expand.

M. W. T.

\section{THE RADIANT POINT OF THE APRIL} LYRIDS.

THE moon being full on the evening of April 22 this year there is little prospect that the shower of Lyrids will assume prominence as a visible spectacle. It should, however, be carefully looked for on the night following April 21, for, notwithstanding the bright moonlight, it is probable that a few fine Lyrids may be observed if the weather is clear. The maximum formerly occurred on April 20, but 1900 not having been a leap year, the epoch of the shower has advanced one day, and must be looked for on April $2 \mathrm{I}$.

There is strong evidence to show that the radiant, like that of the Perseids, moves eastwards with the time, but the Lyrid display is always short-lived and frequently of very feeble character. Moreover, clondy weather sometimes hides the meteors, or moonlight may practically obliterate them, so that it is extremely difficult to determine the exact place of the radiant on several succeeding nights. The April meteors are rarely as abundant as the August Perseids, though there is always the possibility of a brilliant return of the former as in I803, when they fell so plentifully that they could not be counted.

I have collected together all the determinations of the Lyrid radiant which $I$ have met with during the last nine years, and they form a curious medley of positions from which it seems impossible to derive any very exact results :-

Date. Radiant. Meteors. Observer.

I893 April 20 $\left.\begin{array}{r}257+46 \\ 271+42 \\ 278+39\end{array}\right\}$ A. A. Nijland, $\left.\begin{array}{r}271+42 \\ 278+39\end{array}\right\} 47\left\{\begin{array}{r}\text { A. } \\ \text { Utrecht. }\end{array}\right.$ Nijland,

April $20-21 \ldots 267+37 \quad \ldots \quad$ I5 $\}$ H. Corder, Bridg$276+34 \ldots$ Io $\}$ water.

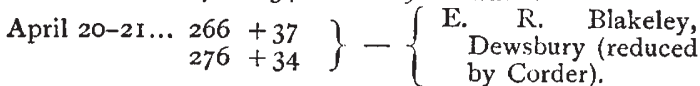

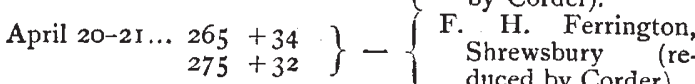

April $20 \quad$ duced by Corder).

$2 I \quad \ldots \quad 273+33 \quad \ldots \quad 8 \%$ Bristol Denning,

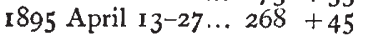

$270+29\} 20\{$ H. Corder, Bridg. $274+33\}^{20}\{$ water.

April I9 $\quad \begin{array}{rrr}285 & 269+32 \\ 21 & \ldots & 274+36\end{array}$

$\left.\begin{array}{ll}\cdots & 9 \\ . . & 8\end{array}\right\}$ E. R. Blakeley,

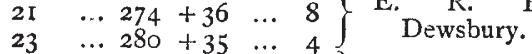

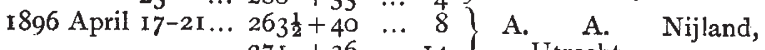

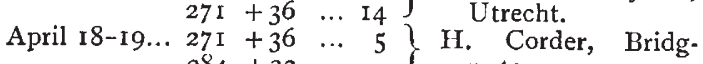

$284+32 \quad \ldots-\}$ water.

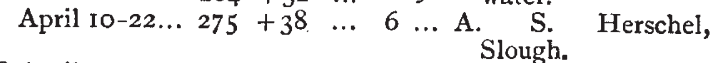

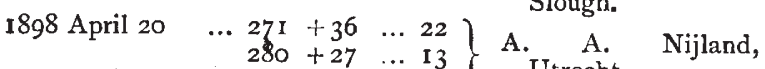

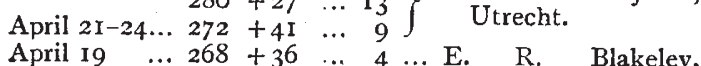

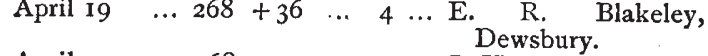

April 19-21... $268+25 \ldots 5 \ldots$ J. H. Bridger, Farn-

April $21-22 \ldots 273 \frac{1}{2}+32 \frac{1}{2} \ldots$ I2 ... W. E. Besley, Lon-

April $12-22 \ldots 270+40 \quad \ldots \quad 5 \ldots$ A. $S$ S. Herschel,

April $20 \quad \ldots 268+37 \quad \ldots \quad 7 \quad \ldots$. J. A. Hardcastle.

NO. I 694, VOL. 65]

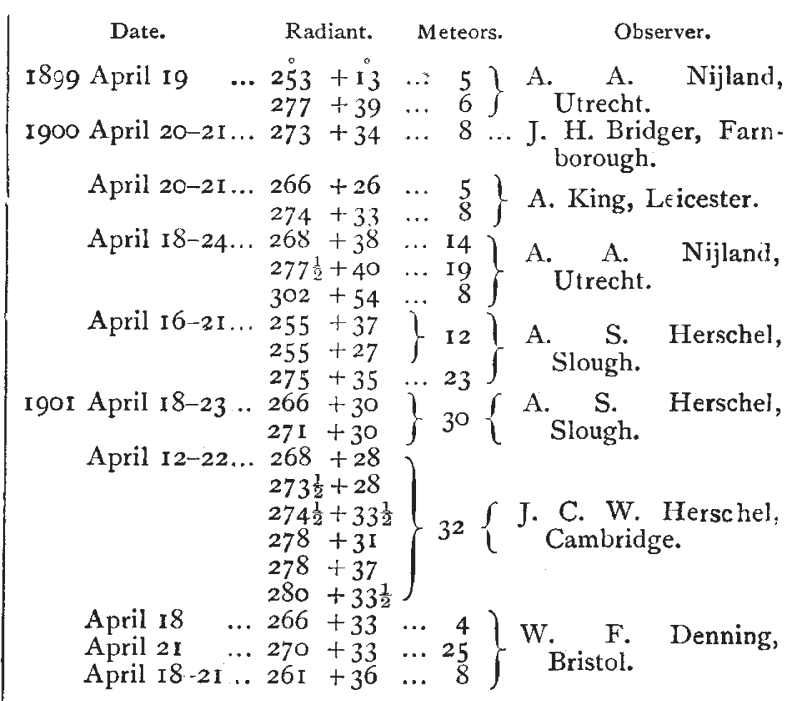

It will be noticed that some of the observers give a multiple radiant, but that the individual positions compared from year to year do not present' a good agreement. At Bristol the radiant has usually been very sharply defined, when the true Lyrids have been sifted from the large number of other meteors directed from showers in nearly the same region of the heavens. The position of the radiant on April 20-2I is at $271^{\circ}+33^{\circ}$, and presents a perfect agreernent with the radiant point of Comet I I86I, with which the Lyrids have long been supposed to be associated.

Some of the positions included in the list represent showers in Hercules and other contemporary streams. Mr. J. C. W. Herschel, from his observations in I9OI, regards the radiant as decidedly multiple, but I believe that further observation will negative this conclusion. There are a considerable number of other meteoric systems in play at the same epoch as the Lyrids, and these, combined with unavoidable errors of observation, must sometimes give rise to apparently scattered radiation and multiple radiants.

W. F. Denning.

\section{UNIVERSITY AND EDUCATIONAL INTE LLIGENCE.}

A $T$ the annual graduation ceremonial of the University of Edinburgh on April I I, Prof. MacGregor, who delivered an address, stated that the suggestion to found a laboratory in memory of the late Prof. Tait had taken practical shape, and that a subscription of $1000 l$. towards this object had been received from an anonymous donor.

SCARCELY a week passes without the announcement in Science of generous gifts to institutions for higher education in the United States. The following are among the gifts recorded during the past few weeks :-Mr. J. D. Rockefeller has given I, 000,000 dollars toward the general endowment fund of the University of Chicago, and 250,000 dollars for the general needs of the University during the present academic year. $\mathrm{He}$ promised a gift to the Harvard Medical School of $1,000,000$ dollars on the condition that 765,000 dollars were collected to meet the sum required for the removal and rebuilding of the school. About 600,000 dollars were subscribed in two weeks, and this was quickly increased to 821,225 dollars, which was more than sufficient to make Mr. Rockefeller's gift available. Mrs. Collis P. Huntington has given 250,000 dollars to the Harvard Medical School to erect a laboratory of pathology and bacteriology in memory of the late Mr. Huntington. Mr. J. Stillman has given 100,000 dollars for the establishment of a chair of anatomy in the same school. Mr. Rockefeller has given 5000 dollars to Washington and Lee University, thus completing the fund of 100,000 dollars for a memorial to the late President William L. Wilson, in the form of an endowment for the chair of economics and political science. Barnard College, Columbia University, has added 500,000 dollars to its endowment, one half having been given by Mr. Rockefeller and the other half having been collected as a condition of this 
gift. Harvard University has received three large bequests: 450,000 dollars from the late Mr. George Smith, 100,000 dollars from the late Mr. Robert C. Billings, and Ioo, 000 dollars from the late Mr. Jacob Wheelock. Mr. Wheelock also bequeathed I00,000 dollars to Clark University, and Mr. Billings bequeathed I00,000 dollars each to the Massachusetts Institute of Technology and the Boston Museum of Fine Arts. The University of Wooster, Wooster, O., successfully completed a campaign to raise 140,000 dollars in order to secure two large conditional gifts, I00,000 dollars by Mr. Andrew Carnegie and 50,000 dollars by Mr. L. H. Severance, of Cleveland. By the will of Mrs. Lila Currier, 50,000 dollars will go to Columbia University and 100,000 dollars to Yale University upon the death of Mr. Edward W. Currier.

AN address on "The Profession of Teaching," delivered recently at Kendal by the Ven. J. M. Wilson, Archdeacon of Manchester and formerly head-master of Clifton College, has been issued by the Kendal Mercury and Times, and it will do a good service by directing attention to desirable objects of education. A school preparation should be of a kind which will foster the desire and develop the power to overcome difficulties; it should give self-reliance and sufficient knowledge of scientific principles to enable the pupil in after life to understand changing conditions and see their trend. Above all, school work should encourage the spirit of inquiry which finds delight in making new observations and experiments with whatever resources are available. The principle upon which Humboldt constructed Prussian education a century ago was : "Whatever we wish to see characteristic of our nation we must first implant in our schools." Remembering this, the teacher's aim should be to give the pupil an observant eye, alert curiosity that inquires into phenomena and their causes, the habit of accurate expression, and varied interests; for then whatever work is afterwards taken up will be satisfactorily done. Archdeacon Wilson strikes the fundamental note of true education in the following remarks from his address :- "The soldier may know all the campaigns of great commanders, from Alexander the Great to Lord Kitchener; but his knowledge avails little unless he has cultivated inventiveness and resource that meets wholly new conditions. The existence of our nation may depend some day on the nerve and originality of the officers of our navy. Every war is a new one; and the next will be utterly unlike the last or the present. It is the same in commerce. The new problems, with combines and international unions, with a shrunken world and new modes of transit, are not like the old. It is the same with agriculture, with mechanical and chemical industries, with engineering. Everything is new, and new every day. It is the same with philosophy and critical studies and theology. It is emphatically the same with statesmanship, municipal and imperial. What utterly new problems in international politics, in international economics and in domestic finance does the world present to-day. Assuredly if we would prepare our scholars for life, the supreme intellectual preparation is found in methods which evoke the faculty, the originality, the mental resourcefulness of our pupils." It is. for us to see that the subjects and methods of teaching in our schools are such as promote the development of these qualities, for national progress depends upon them.

\section{SOCIETIES AND ACADEMIES. LONDON.}

Physical Society, April Ir.-Prof. S. P. Thompson, president, in the chair.-Dr. R. A. Lehfeldt exhibited an electric heater. The apparatus consisted of a vacuum jacketed glass tube, containing water which was boiled by passing a current through a platinum spiràl immersed in the liquid. Tap water is preferable to distilled water, because the small electrolytic action in the former case causes the boiling to proceed quietly. Different temperatures can be obtained by using other liquids. Mr. Grant exhibited and described an apparatus for vapour pressure measurements. The liquid of which the vapour pressure is required is introduced into the vacuum of a syphon barometer. This is mounted alongside an ordinary syphon barometer, and the upper extremities of both are surrounded by a bath, which can be kept at any desired temperature. The levels of the mercury in the open tubes are then adjusted until the upper mercury surfaces are at the same level. The vapour pressure is then measured by the difference of level in the open tubes. By a simple modification it is easy to investigate the vapour pressure of a liquid in the presence of air. The two chief advantages of the method are (I) the simplification of the temperature correction and (2) the wide range of temperature over which it can be employed with the use of a small bath. Prof. Callendar referred to the advantages of the apparatus, and said that it appeared specially suitable for elementary laboratory measurements.-Mr. J. T. Morris showed an experiment illustrating the use of kathode rays in alternate current work. The usual form of Braun tube was used, the rays falling upon a luminescent screen and forming a blue spot. A solenoid conveying an alternating current was fixed near the tube. The varying magnetic field caused the spot to oscillate about its mean position. To determine the maximum value of an alternating current, a switch should be arranged to rapidly replace the alternating current by a continuous one. The continuous current is then adjusted until the maximum excursion of the spot is the same as before and the value of the current read off from an ammeter in the circuit. For accurate work, the frequency of the discharge from the induction coil exciting the tube should be adjusted until it is almost exactly in synchronism with the alternating current. The unsteadiness of the spot of light in the zero position limits the accuracy of the measurements. Mr. Morris has tried to reduce this unsteadiness by using an earthed aluminium diaphragm instead of a glass one.Mr. Morris then showed an experiment on the growth of electric currents in an inductive circuit. An E.M.F. of 0.8 volt was applied to a coil wound on a ring-shaped laminated iron core. When the current had attained its steady value, the E.M.F. was reversed and the variations of the current strength shown by an ammeter. About twenty seconds were required for the current to attain its maximum value in the opposite direction. A secondary coil was also wound upon the same core, and the effect produced upon the growing current by the closing of this secondary circuit was shown. Mr. Morris has determined curves of growth for different currents, and he showed how similar curves could be used to determine experimentally the hysteresis loss in transformers. - Mr. Croft showed some apparatus and devices useful in teaching. The method of determining graphically the focal length of a lens from the distances of conjugate foci from the centre was illustrated. The graphical solution of a quadratic equation was also shown. An apparatus for producing and demonstrating the properties of three-phase currents was exhibited and described. Mr. Croft then showed crystals illustrating the five regular solids, and an electric lainp with the filament in one plane useful for optical work. The flatness of a piece of plate glass can be tested with a scribing block. The point is adjusted to touch the glass in one position. By breathing on the glass and moving the block about it is easily seen if the point leaves the surface.

\section{PARIS.}

Academy of Sciences, April 7.-M. Bouquet de la Grye in the chair. - Note by M. de Freycinet accompanying the presentation of a work on the principles of rational mechanics. On the differentiation of Fourier's series, by M. Leopold Fejer. In general the trigonometrical series, which is obtained by differentiating term by term the Fourier's series of a function $f(x)$, is divergent in the cases which occur most frequently in its applications. A special case of Fourier's series is considered in the present paper, which, when differentiated term by term, is always simply indeterminate, and with the exception of the limits $O$ and $2 \pi$ has for its sum $f^{\prime}(x)$. - On the conditions of stability of automobiles on curves, by M. A. Petot. Formulæ are developed showing the amount of time necessary to pass from one curvature to another. A study of the fundamental conditions arrived at in this paper leads to the conclusion that it is the neglect of these which is the true cause of a number of serious accidents which have been attributed to a faulty steering gear. - Oscillations peculiar to networks of distribution, by M. Brillouin. The theorem deduced by $\mathrm{M}$. Pomey in a recent number of the Comptes rendus was announced and demonstrated fifty-one years ago by Helmholtz. - On the relation $\mathrm{L}+\mathrm{S} / \mathrm{T}=\mathrm{Q} / \mathrm{T}=\mathrm{K}$, by $\mathrm{M}$. de Forcrand. The molecular latent heat of volatilisation of ammonia is calculated by the formula of Clapeyron from the data of Regnault, and this is applied to the proof of a theorem that in all physical and chemical phenomena the heat of solidification of a molecule of a gas is proportional to the absolute temperature of volatilisation under a pressure of 760 $\mathrm{mm}$. of mercury.-On the classification of the atomic weights

NO. I 694, VOL. 65] 